\title{
Can pain influence the proprioception and the motor behavior in subjects with mild and moderate knee osteoarthritis?
}

Daniela C Silveira de Oliveira', Saulo Delfino Barboza', Franciele Dias da Costa², Monnique Ponciano Cabral' Vanessa Martins Pereira Silva ${ }^{2}$ and Valdeci Carlos Dionisio ${ }^{1,2,3^{*}}$

\begin{abstract}
Background: Osteoarthritis $(\mathrm{OA})$ is a chronic disease, usually characterized by pain, which is associated with reduced muscle strength, disability and progressive loss of function. However, the pain influence over proprioception and motor behaviour remains unclear. Thus, the purpose of the study was to identify the levels of pain, the proprioceptive acuity and the pattern of muscle recruitment during stair ascent and descent in elderly patients with mild and moderate osteoarthritis (OA) compared to healthy subjects.

Methods: The study participants included 11 healthy elderly subjects ( 7 women and 4 men) and 31 elderly patients with knee OA (19 women and 12 men). The functional capacity was assessed by the Western Ontario and McMaster Universities (WOMAC) osteoarthritis index; the pain was evaluated by Wong-Baker faces pain rating scale (WBS) and pressure pain threshold (PPT); the proprioceptive acuity was based on the joint position sense evaluated by electrogoniometer; and the electromyographic (EMG) activity of the major muscles of the lower limb were evaluated during a task of stair ascent and descent of $15 \mathrm{~cm}$. For statistical analysis it was used Statistic for Windows software (StatSoft Inc., version 5.0). Data from the WOMAC index, WBS, the proprioceptive acuity and IEMG (for each muscle in each phase) were analyzed using the Mann-Whitney $U$ test and data from PPT was used Kruskal-Wallis test.
\end{abstract}

Results: Higher scores were found in the WOMAC index and WBS whereas lower scores were seen in PPT in patients with knee OA compared to healthy subjects. In contrast, there were no significant differences in the proprioceptive acuity and EMG results of most muscles analyzed between the groups.

Conclusion: The presence of pain does not influence the proprioception and the motor behavior of the thigh muscles during stair ascent and descent in subjects with mild and moderate knee OA.

Keywords: Knee osteoarthritis, WOMAC, Pain, Proprioception, Electromyography

\section{Background}

Osteoarthritis (OA) is a chronic disease that is associated with reduced muscle strength, disability and progressive loss of function, such as walking, climbing up and down stairs, and other tasks of the lower limbs, being the knee joint the most affected. Furthermore, the OA is usually related to pain [1-3].

\footnotetext{
* Correspondence: vcdionisio@gmail.com

'Master Program in Health Sciences, Faculty of Medicine, Federal University of Uberlândia, Uberlândia, Minas Gerais, Brazil

${ }^{2}$ Physical Therapy Course, Faculty of Physical Education, Federal University of Uberlândia, Uberlândia, Minas Gerais, Brazil

Full list of author information is available at the end of the article
}

The weakness of the quadriceps femoris muscle (QF) is a common finding in patients with OA, symptomatic or not [2]. In addition to disuse because of pain, it has also been reported the arthrogenic muscle inhibition (AMI) in OA [4], which along with weakness of the QF muscle, would be linked to inflammation, pain, joint laxity and damaged structures.

The pain may be local, but may also affect distant areas of the knee [5] and become chronic in patients with OA [6]. The progression from acute to chronic nociception is not a fully understood process. Researches in humans [7] and animals [8] suggest that 
peripheral mechanisms in the acute pain and intense nociceptive stimuli on the posterior column of the spinal cord can facilitate the transition from acute to chronic process through metabolic changes and a medullar reorganization [6-8]. Imamura et al. [9] identified clinically widespread hyperalgesia (superficial and deep structures) in disabled subjects due to late knee OA, suggesting that the central and peripheral nervous systems may be involved in the maintenance of chronic pain. Therefore the AMI would be generated by changes in the sensory receptors triggering due to damages in the knee joint and changes in the excitability of spinal pathways [4], which could affect the performance of functional activities.

Kinematic and kinetic studies showed that a greater range of motion (ROM) of the knee is required to climb stairs compared with the level of walking [10]. For the subjects with $\mathrm{OA}$, climbing up and down stairs are more difficult and demanding tasks than walking $[3,11,12]$. However, these subjects may use different movements and patterns of muscle activation, possibly related to pain, when walking and climbing stairs compared to healthy subjects [13-15]. These differences in the movement and kinematic patterns may also be associated with proprioception, since it can influence the movement patterns [16] and motor control. The impaired proprioception may contribute to functional debility [17], reduced accuracy of leg movement [18] and is related to muscle weakness [19].

Here we hypothesized that pain could contribute to proprioceptive deficits and changes in the pattern of muscle recruitment during a task of climbing up and down stairs in subjects with mild and moderate OA. Thus, the aim of this study was to identify the levels of pain, the proprioception and the pattern of muscle recruitment during functional activities, such as climbing up and down stairs in elderly subjects with mild and moderate knee OA compared to healthy subjects.

\section{Methods}

\section{Subjects}

The study participants included 11 healthy elderly subjects ( 7 women and 4 men) and 31 elderly subjects with knee OA (19 women and 12 men). The anthropometric characteristics of the participants are shown in Table 1. The subjects were referred by rheumatologists.

As inclusion criteria for study participation the subjects should be 50 years old or more, presenting knee pain for six months or more, with diagnosis of OA according to the criteria of the American College of Rheumatology [20]. The diagnosis was supported by radiological evidence, with mild or moderate alteration of one or more compartments of the knee, with unilateral or bilateral involvement. The subjects could not present other musculoskeletal disorders, chronic inflammatory diseases as autoimmune diseases (rheumatoid arthritis, lupus, and gout), diabetes mellitus, and neuromuscular disorders as Parkinson's disease, vertigo and other conditions that could affect the sensory capacity and movement control.

Before the start of data collection, the selected subjects were informed about the study and signed an informed consent approved by the Institutional Ethics Committee in Research under number 0012/2010. For all tests, the limb involved or more involved was evaluated.

\section{Assessment of functional quality}

The assessment of pain and physical function of the knee was performed using the Western Ontario and McMaster Universities (WOMAC) osteoarthritis index [21], which outlines the domains of pain, joint stiffness and function.

\section{Pain assessment}

A digital force gauge (Force TEN ${ }^{\text {tis }}$ FDX, Wagner Instruments, Greenwich, CT, USA) with flat head of $1 \frac{2}{2}$ inch in diameter was used for the assessment of superficial and deep pressure pain threshold (PPT) in the knee region [9]. The measurements were performed in myotomes related to the knee (rectus femoris - RF, vastus lateralis - VL, and vastus medialis - VM) and sclerotomes (pes anserinus bursae and patellar tendon). The PPT was expressed in kilograms force (Kgf), with higher values meaning less severe symptoms.

Pain was also assessed by pain scale with 6 faces (Wong-Baker faces pain rating scale - WBS), where the patient marked the face that better described the pain intensity. This scale is numbered from 0 to 5 points [22].

\section{Evaluation of proprioception}

The proprioceptive acuity is based on the joint position sense, which was evaluated according Felson et al. [23]. For this purpose, subjects were asked to sit in a chair, with hips and knees flexed at $90^{\circ}$ and trunk supported. The electrogoniometer was placed on the knee joint, considering the lateral epicondyle of the femur as reference. The subjects were instructed to extend the knee up to find the hand of the investigator (test position) and kept it in this position for 5 seconds. Next, the subjects were asked to return to the initial position of rest, thus remaining for 3 seconds, and then repeat the previous movement, without the presence of the hand of the investigator (playback position) for another 5 seconds. At this time, the subjects were blindfolded and ears covered, and the movement was conducted in 10 different positions. For each repetition, the proprioceptive acuity was considered as the difference between the angles of the knee recorded from the display unit in the test and playback positions [23]. 
Table 1 Anthropometric characteristics of the study subjects

\begin{tabular}{|c|c|c|c|c|}
\hline & Knee OA $(n=31)$ & Healthy $(n=11)$ & & \\
\hline Characteristics & Mean \pm SD & Mean \pm SD & t-value & $p$ value \\
\hline Age (y) & $60.5 \pm 8.9$ & $57.8 \pm 6.2$ & 0.9 & 0.3 \\
\hline Weight (Kg) & $78.0 \pm 13.5$ & $71.7 \pm 15.1$ & 1.2 & 0.2 \\
\hline Height (m) & $1.6 \pm 0.1$ & $1.7 \pm 0.1$ & -0.9 & 0.3 \\
\hline BMI $\left(\mathrm{kg} / \mathrm{m}^{2}\right)$ & $29.6 \pm 4.5$ & $25.9 \pm 3.8$ & 2.4 & $0.01^{\mp}$ \\
\hline \multirow[t]{4}{*}{ Sex distribution } & $\mathrm{F}: \mathrm{n}=11 \mathrm{UI}$ and & $\mathrm{F}: \mathrm{n}=7 ; \mathrm{M}: \mathrm{n}=4$ & -——- & -—— \\
\hline & $\mathrm{n}=7 \mathrm{Bl}$ & & & \\
\hline & $\mathrm{M}: \mathrm{n}=5 \mathrm{UI}$ and & & & \\
\hline & $n=8 \mathrm{Bl}$ & & & \\
\hline
\end{tabular}

OA: osteoarthritis; BMI: Body Mass Index; F: female; M: male; UI: unilateral involvement; BI: bilateral involvement ; ${ }^{\mp}$ Statistical significance.

\section{Electromyographic and kinematic evaluation}

After shaving and cleaning the skin with alcohol, active bipolar surface electrodes (DataHominis Tecnologia Ltda, Uberlândia, Brazil) were fixed on the gastrocnemius lateralis (GL), soleus (SO), tibialis anterior (TA), vastus medialis oblique (VMO), vastus medialis longus (VML), vastus lateralis (VL), and biceps femoris (BF) muscles. For the VMO muscle, the surface electrode was placed on the belly muscle, following the direction of the fibers $[24]$. For the other muscles, the electrodes were placed according to the guidelines of the Surface Electromyography for the Non-Invasive Assessment of Muscles (SENIAM) project [25]. Each electrode consisted of two parallel silver plates $(1 \mathrm{~cm}$ long $\times 1 \mathrm{~mm}$ wide), placed $1 \mathrm{~cm}$ apart. The electrodes had magnification of 20 times, impedance of $10 \mathrm{G} \Omega$ and rejection of $92 \mathrm{~dB}$, and were connected to a computerized device of electromyography (DataHominis Tecnologia Ltda), with a magnification of 100 times (2000 amplification of total time), a pass filter of $15 \mathrm{~Hz}$ to $1 \mathrm{kHz}$ and an acquisition frequency of $2000 \mathrm{~Hz}$.

For movement analysis, it was used an electrogoniometer (EMGsystem) with flexible poles and $270^{\circ}$ rotation, which was placed on the knee joint (lateral epicondyle of the femur). Before starting the evaluation, the channels of the electrogoniometer were calibrated to determine the maximum range of $180^{\circ}$. It was determined $0^{\circ}$ for the full knee extension and any value greater than $0^{\circ}$ for the knee flexion.

\section{Procedures}

After the subjects were submitted to the WOMAC questionnaire, pain and proprioception assessments, they were evaluated by means of electromyography (EMG) recordings during a task of climbing up and down a stair of $15 \mathrm{~cm}$. For this purpose, the subjects were dressed in shorts and shirt, and were instructed to remain standing comfortably in front of the ladder and keep their arms close to the body with the head elevated in order to look forward. To ascent the stair the subjects used first the foot of the evaluated member. To descend from the stair the subjects received the same guidelines, but the nonevaluated member started the downward movement. For each movement, the subjects had a verbal command and seven replicates of each movement (rise or fall) were performed.

\section{Data analysis}

The mean values of EMG activity and kinematics (displacement and angular velocity) were calculated for each of the tasks in the two groups. EMG and kinematic signals were processed offline using the Excel software and KaleidaGraph (rectification, low-pass filter at $25 \mathrm{~Hz}$, normalization of data by the peak of each EMG activity, integral in different phases of the movement - IEMG). These values were calculated for three different phases, based on the angular knee displacement: 300 milliseconds before initiating the movement (P1), from P1 to the knee flexion peak (P2), and from P2 up to the total knee extension (P3).

For statistical analysis it was used Statistic for Windows software (StatSoft Inc., version 5.0). Data from the WOMAC index, WBS, the proprioceptive acuity and IEMG (for each muscle in each phase) were analyzed using the Mann-Whitney $U$ test and data from PPT was used Kruskal-Wallis test. Values of $\mathrm{p} \leq 0.05$ ( $\alpha$ error) were considered statistically significant.

\section{Results and discussion}

Significant differences were found between the groups in the parameters of pain, joint stiffness and function as assessed by the WOMAC index $(\mathrm{p}<0.0001)$ as well as in the subjective pain perception as assessed by WBS $(\mathrm{p}<0.0001)$ (Table 2). Also, PPT assays showed significant differences between the groups in individual values for each myotome and sclerotome $(\mathrm{p}<0.05)$, with the control group presenting lower pain sensitivity, that is, it was more tolerant to pain. In addition, there was a tendency to 
Table 2 WOMAC index, WBS, and PPT, and angular velocity of the knee

\begin{tabular}{|c|c|c|c|}
\hline \multirow[t]{2}{*}{ Variables } & \multirow{2}{*}{$\begin{array}{l}\text { Knee OA }(n=31) \\
\text { Median }(25 \%-75 \%)\end{array}$} & \multirow{2}{*}{$\begin{array}{l}\text { Healthy }(n=11) \\
\text { Median }(25 \%-75 \%)\end{array}$} & \multirow[t]{2}{*}{$p$ value } \\
\hline & & & \\
\hline \multicolumn{4}{|l|}{ WOMAC } \\
\hline Pain & $55(45-60)$ & $0(0-10)$ & $<0.0001^{\mp}$ \\
\hline Stiffness & $50(37.5-62.5)$ & $0(0-0)$ & $0.0001^{\mp}$ \\
\hline Function & $51.5(45.6-7.3)$ & $2.9(0-7.3)$ & $<0.0001^{\mp}$ \\
\hline WBS & $3(2-4)$ & $0(0-0)$ & $<0.0001^{\mp}$ \\
\hline \multicolumn{4}{|l|}{ PPT } \\
\hline \multicolumn{4}{|l|}{ Myotomes } \\
\hline RF & $5.4(3.4-8.0)$ & $10.5(8.2-12.0)$ & $0.0002^{\mp}$ \\
\hline $\mathrm{VL}$ & $3.9(2.6-5.8)$ & $7.5(6.5-8.7)$ & $0.0020^{\mp}$ \\
\hline VM & $4.0(2.9-5.6)$ & $6.7(5.6-8.2)$ & $0.0008^{\mp}$ \\
\hline \multicolumn{4}{|l|}{ Sclerotomes } \\
\hline Pes anserinus bursae & $2.7(1.4-4.8)$ & $7.4(3.5-8.8)$ & $0.0014^{\mp}$ \\
\hline Patellar tendon & $5.6(2.9-8.2)$ & $12.8(9.9-13.8)$ & $0.0002^{\mp}$ \\
\hline \multicolumn{4}{|l|}{ Angular velocity } \\
\hline Stair ascent & $278.9(227.5-317.4)$ & $368.1(269.1-423.4)$ & 0.0600 \\
\hline Stair descent & 162.4 (131.6-198.6) & $157.3(128.4-211.7)$ & 0.8700 \\
\hline
\end{tabular}

Median and 25\%-75\% interquartile range of the variables observed during stair ascent and descent in patients with knee osteoarthritis (OA) and healthy subjects. WOMAC: Western Ontario and McMaster Universities osteoarthritis index; WBS: Wong-Baker faces pain rating scale; PPT: pressure pain threshold; RF: rectus femoris; VL: vastus lateralis; VM: vastus medialis; ${ }^{{ }^{\top}}$ Statistical significance.

have significantly higher values in the angular velocity of the knee during stair ascent, but not stair descent, in healthy subjects compared to patients with knee OA $(\mathrm{p}=0.06)$ (Table 2).

On the other hand, there were no significant differences $(\mathrm{p}=0.23)$ between the groups in values obtained in proprioceptive acuity assays (Figure 1). Likewise, EMG results showed no significant differences in most muscles examined (Table 3), except for the GL muscle in phase 2 $(\mathrm{p}=0.05)$ during stair descent (Figure 2).
Our hypothesis was that pain could contribute to proprioceptive deficits and changes in the pattern of muscle recruitment during a task of climbing up and down stairs. The results do not support our hypothesis, since the pain did not cause a significant change in the pattern of muscle recruitment during a task of climbing up and down stairs, and no change in the proprioceptive acuity.

The higher body mass index (BMI) of the group with knee OA could influence pain, due to increased cartilage degeneration $[26,27]$ in function of substances that

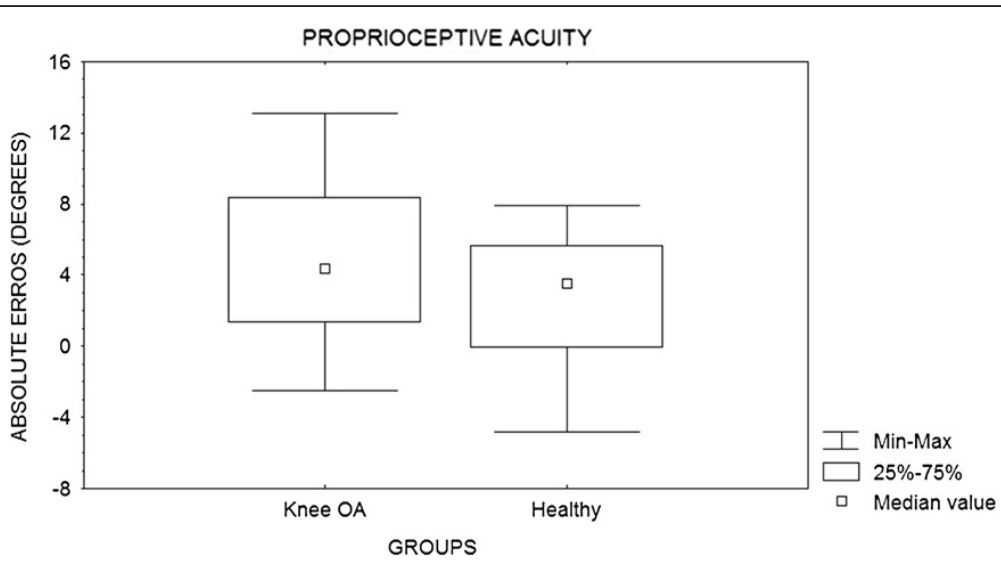

Figure 1 Comparison of proprioception based on the joint position sense between the groups of patients with knee osteoarthritis $(O A)$ and healthy subjects. 
Table 3 Median and 25\%-75\% interquartile range of EMG activity for knee OA and healthy subjects

\begin{tabular}{|c|c|c|c|c|c|c|}
\hline \multirow[b]{2}{*}{ Muscles } & \multicolumn{3}{|c|}{ Stair ascent } & \multicolumn{3}{|c|}{ Stair descent } \\
\hline & Knee OA & Healthy & $p$ value & Knee OA & Healthy & $p$ value \\
\hline & Median & Median & & Median & Median & \\
\hline & $(25-75 \%)$ & $(25-75 \%)$ & & $(25-75 \%)$ & $(25-75 \%)$ & \\
\hline \multirow[t]{2}{*}{$\mathrm{GL}^{1 *}$} & 0.11 & 0.11 & 0.69 & 0.09 & 0.10 & 0.74 \\
\hline & $(0.09-0.16)$ & $(0.08-0.14)$ & & $(0.05-0.16)$ & $(0.04-0.11)$ & \\
\hline \multirow[t]{2}{*}{$\mathrm{SO}^{1}$} & 0.08 & 0.08 & 0.32 & 0.07 & 0.07 & 0.42 \\
\hline & $(0.05-0.09)$ & $(0.06-0.10)$ & & $(0.04-0.10)$ & $(0.06-0.11)$ & \\
\hline \multirow[t]{2}{*}{$\mathrm{TA}^{1}$} & 0.04 & 0.04 & 0.14 & 0.05 & 0.05 & 0.73 \\
\hline & $(0.02-0.06)$ & $(0.04-0.07)$ & & $(0.03-0.07)$ & $(0.04-0.07)$ & \\
\hline \multirow[t]{2}{*}{$\mathrm{VMO}^{1}$} & 0.02 & 0.02 & 0.98 & 0.03 & 0.03 & 0.57 \\
\hline & $(0.01-0.03)$ & $(0.01-0.04)$ & & $(0.02-0.04)$ & $(0.02-0.06)$ & \\
\hline \multirow[t]{2}{*}{$\mathrm{VML}^{1}$} & 0.06 & 0.05 & 0.76 & 0.08 & 0.06 & 0.85 \\
\hline & $(0.04-0.08)$ & $(0.04-0.08)$ & & $(0.05-0.11)$ & $(0.04-0.12)$ & \\
\hline \multirow[t]{2}{*}{$V L^{1}$} & 0.06 & 0.04 & 0.39 & 0.06 & 0.06 & 0.68 \\
\hline & $(0.03-0.08)$ & $(0.03-0.06)$ & & $(0.04-0.09)$ & $(0.03-0.08)$ & \\
\hline \multirow[t]{2}{*}{$\mathrm{BF}^{1}$} & 0.07 & 0.10 & 0.06 & 0.10 & 0.12 & 0.37 \\
\hline & $(0.05-0.11)$ & $(0.08-0.13)$ & & $(0.06-0.13)$ & $(0.06-0.14)$ & \\
\hline \multirow[t]{2}{*}{$G L^{2}$} & 0.20 & 0.16 & 0.11 & 0.48 & 0.32 & $0.05^{\mp}$ \\
\hline & $(0.15-0.32)$ & $(0.09-0.23)$ & & $(0.35-0.82)$ & $(0.22-0.56)$ & \\
\hline \multirow[t]{2}{*}{$\mathrm{SO}^{2}$} & 0.15 & 0.15 & 0.35 & 0.47 & 0.38 & 0.27 \\
\hline & $(0.11-0.21)$ & $(0.08-0.16)$ & & $(0.33-0.62)$ & $(0.21-0.56)$ & \\
\hline \multirow[t]{2}{*}{$\mathrm{TA}^{2}$} & 0.18 & 0.18 & 0.43 & 0.37 & 0.33 & 0.15 \\
\hline & $(0.16-0.21)$ & $(0.15-0.19)$ & & $(0.30-0.50)$ & $(0.22-0.40)$ & \\
\hline \multirow[t]{2}{*}{$\mathrm{VMO}^{2}$} & 0.06 & 0.04 & 0.34 & 0.30 & 0.28 & 0.28 \\
\hline & $(0.03-0.08)$ & $(0.02-0.07)$ & & $(0.25-0.38)$ & $(0.20-0.34)$ & \\
\hline \multirow[t]{2}{*}{$\mathrm{VML}^{2}$} & 0.12 & 0.09 & 0.11 & 0.49 & 0.38 & 0.10 \\
\hline & $(0.09-0.16)$ & $(0.07-0.11)$ & & $(0.35-0.65)$ & $(0.27-0.42)$ & \\
\hline \multirow[t]{2}{*}{$V L^{2}$} & 0.12 & 0.07 & 0.10 & 0.40 & 0.31 & 0.22 \\
\hline & $(0.06-0.19)$ & $(0.04-0.11)$ & & $(0.29-0.57)$ & $(0.26-0.38)$ & \\
\hline \multirow[t]{2}{*}{$\mathrm{BF}^{2}$} & 0.16 & 0.15 & 0.67 & 0.53 & 0.37 & 0.32 \\
\hline & $(0.10-0.22)$ & $(0.11-0.27)$ & & $(0.35-0.64)$ & $(0.30-0.67)$ & \\
\hline \multirow[t]{2}{*}{$\mathrm{GL}^{3}$} & 0.61 & 0.57 & 0.43 & 0.80 & 0.70 & 0.57 \\
\hline & $(0.52-1.06)$ & $(0.48-0.87)$ & & $(0.48-1.17)$ & $(0.56-1.07)$ & \\
\hline \multirow[t]{2}{*}{$\mathrm{SO}^{3}$} & 0.54 & 0.58 & 0.87 & 0.73 & 0.79 & 0.77 \\
\hline & $(0.39-0.76)$ & $(0.47-0.63)$ & & $(0.56-0.81)$ & $(0.55-0.87)$ & \\
\hline \multirow[t]{2}{*}{$\mathrm{TA}^{3}$} & 0.38 & 0.34 & 0.38 & 0.24 & 0.19 & 0.29 \\
\hline & $(0.26-0.62)$ & $(0.24-0.43)$ & & $(0.14-0.33)$ & $(0.15-0.21)$ & \\
\hline \multirow[t]{2}{*}{$\mathrm{VMO}^{3}$} & 0.30 & 0.30 & 0.62 & 0.15 & 0.12 & 0.70 \\
\hline & $(0.25-0.42)$ & $(0.25-0.33)$ & & $(0.10-0.24)$ & $(0.10-0.21)$ & \\
\hline \multirow[t]{2}{*}{$V_{M L}{ }^{3}$} & 0.45 & 0.41 & 0.72 & 0.34 & 0.24 & 0.57 \\
\hline & $(0.39-0.69)$ & $(0.40-0.73)$ & & $(0.23-0.47)$ & $(0.21-0.39)$ & \\
\hline
\end{tabular}


Table 3 Median and 25\%-75\% interquartile range of EMG activity for knee OA and healthy subjects (Continued)

\begin{tabular}{|c|c|c|c|c|c|c|}
\hline \multirow[t]{2}{*}{$V L^{3}$} & 0.49 & 0.40 & 0.24 & 0.26 & 0.20 & 0.36 \\
\hline & $(0.35-0.65)$ & $(0.37-0.48)$ & & $(0.18-0.39)$ & $(0.16-0.31)$ & \\
\hline \multirow[t]{2}{*}{$\mathrm{BF}^{3}$} & 0.56 & 0.59 & 0.33 & 0.40 & 0.36 & 0.35 \\
\hline & $(0.39-0.71)$ & $(0.46-0.87)$ & & $(0.27-0.53)$ & $(0.33-0.61)$ & \\
\hline
\end{tabular}

EMG activity of the gastrocnemius lateralis (GL), soleus (SO), tibialis anterior (TA), vastus medialis oblique (VMO), vastus medialis longus (VML), vastus lateralis (VL), and biceps femoris (BF) muscles of patients with knee osteoarthritis (OA) and healthy subjects during stair ascent and descent. *Superscript numbers in each muscle indicate the phase in which EMG signals were obtained; ${ }^{\mp}$ Statistical significance.

increase the inflammation and can contribute to joint damage $[28,29]$. However, this difference represents values that approximate the level I of the obesity, and even then, did not influence the results, since the proprioceptive acuity and pattern of muscle recruitment were similar to the healthy group.

The presence of pain in patients with OA may have different mechanisms, like the mechanical tension on the nociceptors by local pressure or joint movement, irritation of nociceptors by inflammatory mediators [30], muscle contraction, QF weakness and joint effusion [4,31]. The synovium, periosteum, subchondral bone, infrapatellar fat purse, and joint capsule are also structures that produce pain $[28,32]$. The experimentally induced pain has indicated that it may have some influence on the proprioceptive system [33]. Chemicals substances produced in response to pain may sensitize free nerve endings, resulting in abnormal discharge of pain afferents. This could influence the motoneuron gamma, and consequently the activity of the muscle spindle, thus interfering with the proprioceptive entry [16]. Although pain is present in the subjects analyzed in our study, it had no influence on the proprioception. This suggests that proprioceptive acuity in subjects with knee OA may result from factors other than pain, like damages or reduction of the mechanoreceptors [31] and capsuloligamentous changes [16], like the ones in the OA more severe [34].
In our study, the participants with knee OA had mild or moderate levels and tissue was less damage than severe OA. For mild OA it was observed the lack of the correlation between muscle force and knee joint loading during gait [35]. This could also contribute not to support the hypothesis proposed by van der Esch et al. [19], which proprioception is related to muscle weakness and functional ability. The relationship between proprioceptive acuity and muscle force can be dependent on the level of severity of the OA and or pain.

More recently, research has begun to focus on other different mechanisms by which could lead to knee pain and they are classified into central and peripheral pathways [5]. Peripheral sensitization occurs when peripheral nociceptive afferents become spontaneously more active and cause local pain, so-called "primary hyperalgesia". On the other hand, central sensitization is involved with referred pain and allodynia in a location away from the involved joint, with increased excitability and/or decreased inhibition at cortical or spinal level. The term "secondary hyperalgesia" refers to increased sensitivity of neurons in the posterior spinal cord in the corresponding segments to the primary site [36]. Likewise it was observed a lack of correlation between the radiological findings and pain [6]. The pain in OA also demonstrates an activation of the prefrontal cortex limbic region, suggesting that this region, also associated with emotional responses, may play a role

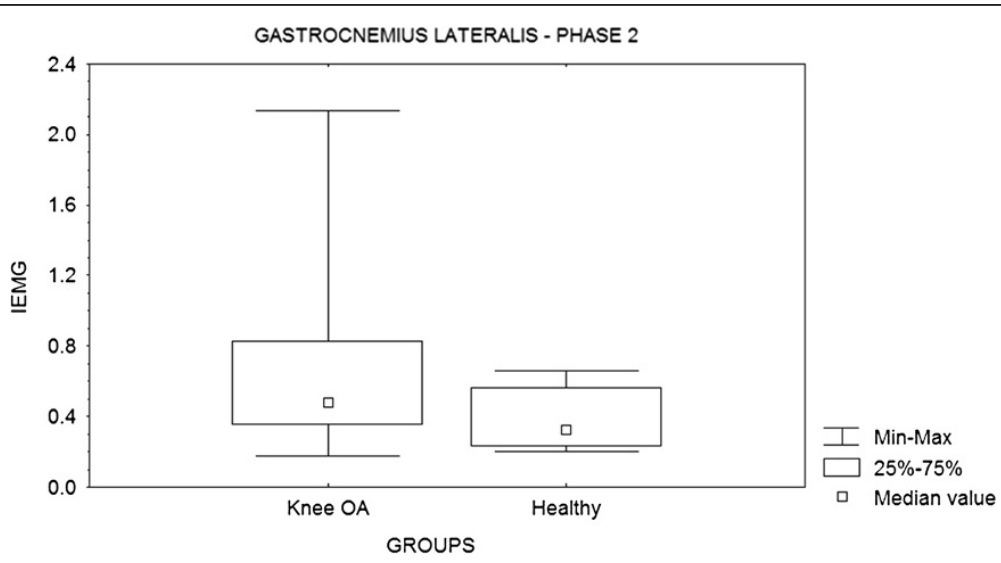

Figure 2 Comparison between EMG values obtained from the gastrocnemius lateralis muscle of patients with knee osteoarthritis (OA) and healthy subjects during descent from a stair (phase 2). 
in the generation of pain in OA [36]. Acute pain is usually self-limited and serves as a protective biological function, but chronic pain, in contrast, has no protective biological function, is not self-limiting, and can persist for years after the initial injury, and may also be more refractory to several modalities of treatment [6]. The participants of this study had at least six months pain history due to knee OA, suggesting a chronic pain and they might have developed a secondary hyperalgesia [31]. Thus, in the presence of chronic pain, subjects with knee OA could have other symptoms related to emotional issues, such as anxiety, difficulty in sleeping, depression [6], factors that were not analyzed in our study, but could have some kind of influence in the presence of pain in these subjects [37].

The biomechanical mechanisms or strategies could also justify the similarity in performing the task of climbing up and down stairs. The trunk could have been flexed, thus reducing the knee torque extensor [38,39]. Fok et al. [39] observed that there is a greater anterior pelvic inclination and a smaller flexion angle, and lower knee extension time in both stair ascent and descent. This could be considered a limitation of the present study, since even though the subjects were instructed to remain upright, the trunk movements were not monitored, which may have contributed to our results.

Regarding the EMG results of the muscles analyzed, only the GL muscle of subjects with knee OA showed increased muscle activation during stair descent (phase 2) compared to healthy subjects. In the proposed task the assessed limb was the supporting limb, while the opposite limb reached the bottom stair. The increased activation of the GL muscle may be associated with an isometric contraction, since there are simultaneous knee flexion and ankle dorsiflexion, contributing for joints stabilization, which can cause control of the anterior displacement of the tibia. This observation is similar to the one observed in others studies during squats [24]. So, the GL facilitated slowing the movement of knee flexion, facilitating the execution of the activity. Likewise, Hortobágyi et al. [40] found that the rates of activation of the GL and TA muscles were significantly higher in subjects with OA than in healthy adults and young adults, with large variation between individuals. However, it is not possible to say that the pain has not influenced this activation.

Finally, another factor that may have influenced the muscle activation during stair ascent and descent in our study is that motor activity is time-dependent $[15,41,42]$. In this study a strong trend was observed for reducing velocity in stair ascent in subjects with knee OA. The reduction in gait velocity has been suggested as a possible method used by people with OA to reduce the loads on the knee $[41,42]$.

Although the self-selected velocity and no control of trunk movements can be considered as limitations of the study, the results are consistent with previous studies $[6,16,31,40]$. Another possible limitation is the small sample, however, it is consistent with early studies $[3,15,17]$. The results of this study suggest that there is loss of association of pain with proprioceptive acuity and muscle activity during a functional task, which could be compensated by physiological and biomechanical mechanisms. This study also indicates that the pain in knee OA involves other physiological variables, which can lead to increased pain and functional decline.

\section{Conclusion}

Although the pain is present in subjects with mild and moderate knee OA, it does not influence the proprioception and the motor behavior of the thigh muscles during stair ascent and descent.

\section{Abbreviations}

OA: Osteoarthtitis; AM: Arthrogenic muscle inhibition; QF: Quadriceps femoris; ROM: Range of motion; WOMAC: Western Ontario and McMaster Universities; PPT: Pressure pain threshold; RF: Rectus femoris; VL: Vastus lateralis; VM: Vastus medialis; Kgf: Kilograms force; WBS: Wong-Baker scale; GL: Gastrocnemius lateralis; SO: Soleus; TA: Tibialis anterior; VMO: Vastus medialis oblique; VML: Vastus medialis longus; BF: Biceps femoris; SENIAM: Surface Electromyography for the Non-Invasive Assessment of Muscles; EMG: Electromyography; IEMG: Integrated electromyography; BMl: Body mass index.

\section{Competing interests}

All authors declare that they have no competing interests.

\section{Authors' contributions}

DCSO, SDB, FDC, MPC, VMPS and VCD conceived and designed the study, participated in the data acquisition, performed the analysis and interpretation of the data and drafted the manuscript. DCSO, VMPS and VCD participated in the data acquisition and drafting of the manuscript. DCSO and VCD performed the analysis and interpretation of data and performed a critical review of the manuscript for intellectual content. All authors read and approved the final manuscript.

\section{Acknowledgements}

We thank the Fundação de Amparo à Pesquisa do Estado de Minas Gerais (FAPEMIG), for their support.

\section{Author details}

${ }^{1}$ Master Program in Health Sciences, Faculty of Medicine, Federal University of Uberlândia, Uberlândia, Minas Gerais, Brazil. ${ }^{2}$ Physical Therapy Course, Faculty of Physical Education, Federal University of Uberlândia, Uberlândia, Minas Gerais, Brazil. ${ }^{3}$ Mailing Address: Rua Benjamin Constant, 1286, Aparecida, Uberlândia, Minas Gerais, Brazil.

Received: 8 July 2014 Accepted: 25 September 2014 Published: 27 September 2014

\section{References}

1. Guccione AA, Felson DT, Anderson JJ, Anthony JM, Zhang Y, Wilson PW, Kelly-Hayes M, Wolf PA, Kreger BE, Kannel WB: The effects of specific medical conditions on the functional limitations of elders in the Framingham Study. Am J Public Health 1994, 84(3):351-358.

2. Felson DT, Zhang Y: An update on the epidemiology of knee and hip osteoarthritis with a view to prevention. Arthritis Rheum 1998, 41(8):1343-1355

3. Hinman RS, Bennell KL, Metcalf BR, Crossley KM: Delayed onset of quadriceps activity and altered knee joint kinematics during stair stepping in individuals with knee osteoarthritis. Arch Phys Med Rehabil 2002, 83(8):1080-1086. 
4. Rice DA, McNair PJ: Quadriceps arthrogenic muscle inhibition: neura mechanisms and treatment perspectives. Semin Arthritis Rheum 2010, 40(3):250-266

5. Susko AM, Fitzgerald GK: The pain-relieving qualities of exercise in knee osteoarthritis. Open Access Rheumatol Res Rev 2013, 5:81-91.

6. Haviv B, Bronak S, Thein R: The complexity of pain around the knee in patients with osteoarthritis. Isr Med Assoc J 2013, 15(4):178-181.

7. Klein T, Magerl W, Hopf HC, Sandkühler J, Treede RD: Perceptual correlates of nociceptive long-term potentiation and long-term depression in humans. J Neurosci 2004, 24(4):964-971.

8. Schadrack J, Neto FL, Ableitner A, Castro-Lopes JM, Willoch F, Bartenstein P, Zieglgänsberger W, Tölle TR: Metabolic activity changes in the rat spinal cord during adjuvant monoarthritis. Neuroscience 1999, 94(2):595-605.

9. Imamura M, Imamura ST, Kaziyama HH, Targino RA, Hsing WT, de Souza LP, Cutait MM, Fregni F, Camanho GL: Impact of nervous system hyperalgesia on pain, disability, and quality of life in patients with knee osteoarthritis: a controlled analysis. Arthritis Rheum 2008, 59(10):1424-1431.

10. Protopapadaki A, Drechsler WI, Cramp MC, Coutts FJ, Scott OM: Hip, knee, ankle kinematics and kinetics during stair ascent and descent in healthy young individuals. Clin Biomech (Bristol, Avon) 2007, 22(2):203-210.

11. Guo M, Axe MJ, Manal K: The influence of foot progression angle on the knee adduction moment during walking and stair climbing in pain free individuals with knee osteoarthritis. Gait Posture 2007, 26(3):436-441.

12. Liikavainio T, Bragge T, Hakkarainen M, Karjalainen PA, Arokoski JP: Gait and muscle activation changes in men with knee osteoarthritis. Knee 2010, 17(1):69-76

13. Kaufman KR, Hughes C, Morrey BF, Morrey M, An KN: Gait characteristics of patients with knee osteoarthritis. J Biomech 2001, 34(7):907-915.

14. Childs JD, Sparto PJ, Fitzgerald GK, Bizzini M, Irrgang JJ: Alterations in lower extremity movement and muscle activation patterns in individuals with knee osteoarthritis. Clin Biomech (Bristol, Avon) 2004, 19(1):44-49.

15. Hicks-Little CA, Peindl RD, Fehring TK, Odum SM, Hubbard TJ, Cordova ML: Temporal-spatial gait adaptations during stair ascent and descent in patients with knee osteoarthritis. J Arthroplasty 2012, 27(6):1183-1189.

16. Bennell KL, Hinman RS, Metcalf BR, Crossley KM, Buchbinder R, Smith M, McColl G: Relationship of knee joint proprioception to pain and disability in individuals with knee osteoarthritis. J Orthop Res 2003, 21(5):792-797.

17. Pai YC, Rymer WZ, Chang RW, Sharma L: Effect of age and osteoarthritis on knee proprioception. Arthritis Rheum 1997, 40(12):2260-2265.

18. Williamson EM, Marshall PH: Effect of osteoarthritis on accuracy of continuous tracking leg movement. Percept Mot Skills 2014, 118(1):162-182.

19. van der Esch M, Steultjens M, Harlaar J, Knol D, Lems W, Dekker J: Joint proprioception, muscle strength, and functional ability in patients with osteoarthritis of the knee. Arthritis Rheum 2007, 57(5):787-793.

20. Altman R, Asch E, Bloch D, Bole G, Borenstein D, Brandt K, Christy W, Cooke TD, Greenwald R, Hochberg M: Development of criteria for the classification and reporting of osteoarthritis: Classification of osteoarthritis of the knee: Diagnostic and Therapeutic Criteria Committee of the American Rheumatism Association. Arthritis Rheum 1986, 29(8):1039-1049.

21. Gandhi R, Tsvetkov D, Dhottar H, Davey JR, Mahomed NN: Quantifying the pain experience in hip and knee osteoarthritis. Pain Res Manag 2010, 15(4):224-228

22. Bashir MS, Khade A, Borkar P, Saleem M, Lingaswamy V, Reddy D: A comparative study between different pain rating scales in patients of osteoarthritis. Indian J Physiol Pharmacol 2013, 57(2):205-208.

23. Felson DT, Gross KD, Nevitt MC, Yang M, Lane NE, Torner JC, Lewis CE, Hurley MV: The effects of impaired joint position sense on the development and progression of pain and structural damage in knee osteoarthritis. Arthritis Rheum 2009, 61(8):1070-1076.

24. Dionisio V, Almeida G, Duarte M, Hirata R: Kinematic, kinetic and EMG patterns during downward squatting. J Electromyogr Kinesiol 2008, 18(1):134-143

25. Hermens HJ, Freriks B, Disselhorst-Klug C, Rau G: Development of recommendations for SEMG sensors and sensor placement procedures. J Electromyogr Kinesiol 2000, 10(5):361-374.

26. Felson DT, Anderson JJ, Naimark A, Walker AM, Meenan RF: Obesity and knee osteoarthritis: the Framingham Study. Ann Intern Med 1988, 109(1):18-24.

27. Widmyer MR, Utturkar GM, Leddy HA, Coleman JL, Spritzer CE, Moorman CT, DeFrate LE, Guilak F: High body mass index is associated with increased diurnal strains in the articular cartilage of the knee. Arthritis Rheum 2013, 65(10):2615-2622.

28. Conde J, Scotece M, Gómez R, Lopez V, Gómez-Reino JJ, Gualillo O: Adipokines and osteoarthritis: novel molecules involved in the pathogenesis and progression of disease. Arthritis 2011, 2011:203901.

29. Sokolove J, Lepus CM: Role of inflammation in the pathogenesis of osteoarthritis: latest findings and interpretations. Ther Adv Musculoskelet Dis 2013, 5(2):77-94.

30. Zimmermann M: Pain mechanisms and mediators in osteoarthritis. Semin Arthritis Rheum 1989, 18(4 Suppl 2):22-29.

31. Hassan BS, Doherty SA, Mockett S, Doherty M: Effect of pain reduction on postural sway, proprioception, and quadriceps strength in subjects with knee osteoarthritis. Ann Rheum Dis 2002, 61(5):422-428.

32. Kidd BL: Osteoarthritis and joint pain. Pain 2006, 123(1-2):6-9.

33. Capra NF, Ro JY: Experimental muscle pain produces central modulation of proprioceptive signals arising from jaw muscle spindles. Pain 2000, 86(1-2):151-162

34. Baert IA, Mahmoudian A, Nieuwenhuys A, Jonkers I, Staes F, Luyten FP, Truijen S, Verschueren SM: Proprioceptive accuracy in women with early and established knee osteoarthritis and its relation to functional ability, postural control, and muscle strength. Clin Rheumatol 2013, 32(9):1365-1374.

35. Baert IA, Jonkers I, Staes F, Luyten FP, Truijen S, Verschueren SM: Gait characteristics and lower limb muscle strength in women with early and established knee osteoarthritis. Clin Biomech (Bristol, Avon) 2013, 28(1):40-47.

36. Lluch Girbés E, Nijs J, Torres-Cueco R, López Cubas C: Pain treatment for patients with osteoarthritis and central sensitization. Phys Ther 2013 , 93(6):842-851

37. Wise BL, Niu J, Zhang Y, Wang N, Jordan JM, Choy E, Hunter DJ: Psychological factors and their relation to osteoarthritis pain. Osteoarthritis Cartilage 2010, 18(7):883-887.

38. Asay JL, Mündermann A, Andriacchi TP: Adaptive patterns of movement during stair climbing in patients with knee osteoarthritis. J Orthop Res 2009, 27(3):325-329.

39. Fok LA, Schache AG, Crossley KM, Lin YC, Pandy MG: Patellofemoral joint loading during stair ambulation in people with patellofemoral osteoarthritis. Arthritis Rheum 2013, 65(8):2059-2069.

40. Hortobágyi T, Westerkamp L, Beam S, Moody J, Garry J, Holbert D, DeVita P: Altered hamstring-quadriceps muscle balance in patients with knee osteoarthritis. Clin Biomech (Bristol, Avon) 2005, 20(1):97-104.

41. Robon MJ, Perell KL, Fang M, Guererro E: The relationship between ankle plantar flexor muscle moments and knee compressive forces in subjects with and without pain. Clin Biomech (Bristol, Avon) 2000, 15(7):522-527.

42. Mündermann A, Dyrby CO, Hurwitz DE, Sharma L, Andriacchi TP: Potential strategies to reduce medial compartment loading in patients with knee osteoarthritis of varying severity: reduced walking speed. Arthritis Rheum 2004, 50(4):1172-1178.

doi:10.1186/1471-2474-15-321

Cite this article as: de Oliveira et al.: Can pain influence the proprioception and the motor behavior in subjects with mild and moderate knee osteoarthritis?. BMC Musculoskeletal Disorders 2014 15:321.

\section{Submit your next manuscript to BioMed Central and take full advantage of:}

- Convenient online submission

- Thorough peer review

- No space constraints or color figure charges

- Immediate publication on acceptance

- Inclusion in PubMed, CAS, Scopus and Google Scholar

- Research which is freely available for redistribution 